\title{
Ocean warming hotspots provide early warning laboratories for climate change impacts
}

\author{
Gretta T. Pecl • Alistair J. Hobday • \\ Stewart Frusher - Warwick H. H. Sauer • \\ Amanda E. Bates
}

Published online: 4 May 2014

(C) Springer International Publishing Switzerland 2014

A growing literature describes a wide range of negative impacts of climate change on marine resources and the people and communities they support, including species range changes, changes in productivity of fisheries and declines in economic performance (Doney et al. 2012; Poloczanska et al. 2013). These impacts, many of which are projected to increase in future, are compounded by growing pressures on marine resources (Halpern et al. 2008; Maxwell et al. 2013). An estimated 260 million people are involved directly or indirectly in global marine fisheries (Teh and Sumaila 2013) with many of the resources for capture fisheries already fully $(\approx 57 \%$ in 2009) or over exploited (30\%) (FAO 2012). Nevertheless, production of marine resources will

\section{G. T. Pecl $(\bowtie) \cdot$ S. Frusher}

Institute for Marine and Antarctic Studies, University of Tasmania, Private Bag 49, Hobart, TAS 7001, Australia e-mail: Gretta.Pecl@utas.edu.au

A. J. Hobday

CSIRO Marine and Atmospheric Research, GPO Box 1538, Hobart, TAS 7001, Australia

W. H. H. Sauer

Department of Ichthyology and Fisheries Science, Rhodes University, P.O. Box 94, Grahamstown 6140,

South Africa

A. E. Bates

Ocean and Earth Science, National Oceanography Centre Southampton, University of Southampton, Southampton SO14 3ZH, UK need to increase to accommodate the demands of a growing population, and the impacts of climate change on food security will need to be minimised (FAO 2009). Identifying opportunities and threats, and developing adaptation options in response to climate change impacts in the marine realm, is essential for optimising the benefits that society can continue to derive from the goods and services provided by marine resources.

The oceans are not warming evenly and those areas that are warming the fastest, ocean warming 'hotspots', can be considered in many contexts as the world's natural laboratories to provide the knowledge and tools to enable us to adapt wisely, efficiently and effectively to meet the challenges of a warming environment. Having identified the 24 fastest warming regions globally (Hobday and Pecl, 2013), a 2010 workshop was held in Sendai, Japan attended by scientists working in these hotspot regions. These scientists confirmed that many similar impacts were being reported across these regions, yet many were not formally documented. It was also apparent that approaches for adjusting to these changes, i.e. the development of adaptation options in the human realm, were difficult, and only just beginning to be considered (Pecl et al. 2010). Consensus from this meeting was the need for the marine climate change community to be better connected and for lessons from each of the regions to be shared as a potential way to facilitate and improve adaptation science globally. One way of improving these linkages is via a 
coordinated network linking global marine hotspots that can (1) facilitate comparative studies through promotion of consistency in data collection, analysis and reporting, (2) provide improved understanding of current and anticipated impacts for stakeholders, (3) allow greater certainty in ecological/ecosystem model projections through first opportunities for model validation and (4) provide learning opportunities for scientists, managers and policy makers to establish how climate change science can be translated effectively into policy and practical adaptive management measures. The subsequent formation of a global marine hotspots network (www.marinehotspots.org) has been followed by several meetings at international symposia and workshops (e.g. Aberdeen 2012, Korea 2012-see Pecl et al. 2012; and others). Identifying hotspot regions is just the starting point for international collaboration, providing a framework to synthesise and compare emerging knowledge, facilitate access to national, regional and international funding opportunities, and the opportunity to shape global conservation and management objectives (de Sherbi$\operatorname{nin}$ 2014). Moreover, rapidly warming regions are one facet of change that can be integrated with other data layers for identifying and learning from other 'natural laboratories', for example, regions with higher rates of acidification, greater exposure to sea level rise or greater sensitivity to change. Whilst the multiple drivers of climate change do not operate in isolation, the principle being tested here is that analysis of regions with a key challenge in common-in this case exposure to rapid rates of temperature change-can facilitate learning of how to address those challenges more effectively.

The 11 articles within this special issue represents a compendium of studies in ocean warming hotspots that range from detailed descriptions of biological impacts and responses and the mechanisms underpinning these, through to evaluation of the flexibility of fisheries management and fishery fleets to respond to ecological changes. A common theme is the need for trans-disciplinary and participatory approaches to effectively engage stakeholders within these regions (Frusher et al. 2013).

Many of the 'hotspot' regions identified by Hobday and Pecl (2013) were associated with western boundary currents (and see Wu et al. 2012). Changes in the strength and intensity of boundary currents can underpin dynamics in primary production, instigate changes in phytoplankton dynamics leading to trophic and phenological mismatches, and lead to a reorganization of marine ecosystems (Matear et al. 2013). Buchanan et al. (2013) look at a rapidly warming region in south east Tasmania, Australia where two poleward boundary currents interact. They report range extensions of several subtropical species of phytoplankton, presumably due to the increasing penetration of the warm poleward East Australian Current south to Tasmania. In combination with this subtropical influence, the authors further demonstrate the potential for incursions of subantarctic water and associated species into Tasmania during the summer months. In other boundary current regions, similar oceanographic dynamics may also create mixed phytoplankton communities, with the potential for significant biological change at the base of the food chain.

Several contributions to the special issue detail changes in the distributions of higher trophic level species. Rapid temperature change in global marine hotspots will challenge fisheries management due to life history changes, such as size at maturity, changes in relative abundance, and the redistribution of target and bycatch species (Hobday et al. 2008; Brander 2010, Bates et al. 2014). Jung et al. (2013) illustrate some of these observed patterns in species distribution using commercial catch data from Korean waters. They showed that mean latitude of the catch distribution was related to water temperature for seven of the 12 species examined over a 30 year period. Projections of species distribution for the 2030's show continued poleward shifts in distribution, although these were moderated by heterogenous warming patterns and a convoluted coastline. Yemane et al. (2014) analysed a historical 25 year dataset from trawl surveys undertaken in the Benguela Current Large Marine Ecosystem and found that while there were distributional changes within the fish community, there was no consistency in the latitudinal change in distribution with sea surface temperature (SST) and instead more species appeared to be moving to deeper water. Additionally, bottom temperatures, although patchy for several regions, showed a different pattern of change compared to SST. The complexity of the ocean currents around south West Africa, and different warming trends for surface and bottom waters, highlights the need for comprehensive sampling protocols to obtain the detailed physical and biological data 
necessary to decipher the drivers of complex changes in species distributions and discern variability from trend (Hobday and Evans 2013).

Morley et al. (2013) related the physiological tolerances of species to a range of impacts that warming can have on species. Regions with rapidly changing climate, particularly if they coincide with regions with a high incidence of range limits, such as the sub-Antarctic Island of South Georgia, are important locations for making rapid advances in our mechanistic understanding of the factors driving these changes. Morley et al. discuss how climate-driven changes in the ecosystem can impact on fisheries, and highlight that in order to allocate quotas for sustainable harvests, it is important to incorporate species vulnerabilities to climate that will underlie likely changes in population dynamics. Potts et al. (2013) provide an additional example of how biological attributes-reproductive scope in this case, can drive changes in distribution, especially for reproductively stenothermal species as waters warm. As per Morley et al. (2013), future management decisions would need to incorporate climate impacts, especially when recovery from overfishing is the goal (i.e. without accounting for the global warming impacts, recovery may not occur at the expected rate, despite effort reductions). Moreover, the authors link anomalous cold years and reproductive longevity, offering a novel insight that can be examined in other regions that are expected to be impacted by extreme cold, such as the UK. While a gradual increasing trend in warming temperatures may see the reproductive scope for a species decline due to localised extinction, an anomalous cold year would see a successful reproductive year. Thus for long lived species, the probability of an anomalous year for successful reproduction under these conditions increases with time.

Mangubhai et al. (2013) demonstrates that an extreme heat event can also drive negative and large-scale community change within a region of rapid warming. They provide an analysis of reef fish community structure following a prolonged period of elevated temperature that corresponded with coral bleaching in the Phoenix Islands. Their analysis is unique in focusing on a remote region where attempts to identify the effects of coral bleaching are therefore relatively uninfluenced by human activity. Although the responses among fish families and among habitats were highly variable, possibly due to an indirect effect or a lag in community-level responses following the thermal stress event, they found an overall decline in coral cover and fish abundance following bleaching.

Given the diverse biological responses expected due to the dynamic nature of warming across space and time, and the additional physical parameters that are expected to change, Okey et al. (2013) provide a detailed summary of the current status of Canada's Pacific marine ecosystems and consider challenges in prediction and adaptation. The authors point out that despite long-term warming, SST have been relatively cool since 2007, typical of La Niña-type conditions. However, when warmer El Niño conditions prevail, waters become more acidic and depleted of oxygen due to the weakening ventilation of subsurface waters resulting from increased stratification. During El Nino events, southern species are observed in the region. Diverse biological responses to these changes are therefore expected, and the authors highlight the challenges in forecasting the responses of key species, and in mapping climate vulnerabilities accurately enough to help prioritize and guide adaptation planning (see also de Sherbinin 2014).

To evaluate if fishery managers in hotspot regions are already using tools that will assist adaptation to biological changes, Melnychuk et al. (2013) investigated the adaptability of fisheries management systems in relation to oceanic warming rates for $>500$ stocks around the world. In particular, use of harvest control rules may provide the capacity for harvest policies to change in response to climate-driven abundance declines while seasonal openings with flexible dates may allow managers to better respond to possible changes in the timing of life-history periods. Harvest control rules were not used more often in fast warming areas, however, flexible-date seasonal openings tended to occur in areas with the greatest warming rates. Melnychuk et al. (2013) also concluded that hotspot regions contain fisheries that demonstrate the potential for adaptability to unpredictable climate impacts. Moreover, a case study in the rapidly warming region of south east Australia by Hamon et al. (2013) demonstrates fisheries will need to respond to market conditions as well as the direct impacts of environmental changes. The fishery for southern rock lobster (Jasus edwardsii) operates within the south east Australian hotspot off the east coast of Tasmania. Hamon et al. (2013) point out that the future of the Tasmanian rock lobster fishery is 
highly uncertain due to climate change, but also due to insecurities linked to the market conditions. Three fleet dynamic models of increasing complexity were used to investigate the effects of climate change and lobster price changes on the fishery. Best outcomes were shown to occur if the fleet adapts dynamically to environmental conditions, and fishing effort follows stock abundance, which would counter-act the shortterm effects of climate change. The authors reflect on the fact that only a model with explicit representation of economic drivers can fully capture the local economic and social impacts of large scale global perturbations. However, holistic adaptation to the impacts of climate change within our marine ecosystems and fisheries, and the flow-on effects to communities, will require a trans-disciplinary approach that translates the physical and biological impacts of climate change in a context that end users understand. This invariably requires an understanding and acknowledgement of the values and needs of communities, industries and governments if adaptation options are to be effective and supported. Frusher et al. (2013) describes how research in the south east Australian marine hotspot has evolved from a multidisciplinary to inter-disciplinary and trans-disciplinary approach to effectively engage stakeholders.

Hotspot regions identified by Hobday and Pecl (2013) are located in countries with a variety of traditional, artisanal, subsistence and industrialised fisheries, and unique biodiversity from tropical to polar regions. Hotspot regions therefore provide an ideal opportunity to progress towards a more holistic approach to resource management and represent ideal locations for testing the generic value of new methodologies and approaches to adjust to climate change impacts. Nonetheless, the application of the approach to, and outcomes from, other ocean warming hotspot regions needs to be co-ordinated and achievements in community, industry and government outcomes demonstrated as adaptation pathways commence. Improved monitoring of outcomes and investing (e.g. training) in people who can bridge the differing disciplines remains a key need for progressing transdisciplinary approaches and such training will need to target managers and industry leaders as well as researchers. As early learning laboratories, global hotspots will need to be able to demonstrate globally relevant outcomes associated with a range of industries, communities and governments as climate change impacts marine systems. Importantly, these "laboratories" will be the best placed to identify solutions or constructive approaches to address challenges as increased pressure is placed on the marine environment to ensure food security for a rapidly increasing global community (Rice and Garcia 2011).

Collectively, these papers within the 'Global Marine Hotspots Special Issue' highlight significant biological responses in rapidly warming regions that directly link to food production (fisheries) and therefore to the livelihoods of people that depend on them. Understanding the impacts of warming temperatures and other climate drivers on marine systems will be important for sustainable management of human interactions with fisheries and ecosystems. Ocean warming hotspots can serve as natural laboratories to help build our understanding of biological, social and economic climate-driven changes. However, the rapid rate of ocean change means that adaptation in the human realm must occur in concert with developing a full biological understanding and thus further and immediate research on the effective development of adaptation options for marine systems is needed.

\section{References}

Bates AE, Pecl GT, Frusher S, Hobday AJ, Wernberg T, Smale DA, Dulvy N, Edgar GJ, Feng M, Fulton EA, Hill N, Holbrook NJ, Radford B, Slawinski D, Sunday JM, Thompson PA, Watson R (2014) Evaluating pathways of geographic range extensions and contractions. Glob Environ Change 26:27-38

Brander K (2010) Impacts of climate change on fisheries. J Marine Syst 79:389-402

Buchanan PJ, Swadling KM, Eriksen RS, Wild-Allen K (2013) New evidence links changing shelf phytoplankton communities to boundary currents in southeast Tasmania. Rev Fish Biol Fish. doi:10.1007/s11160-013-9312-z

de Sherbinin A (2014) Climate change hotspots mapping: what have we learned? Clim Change 123:23-37

Doney SC, Ruckelshaus M, Duffy JE, Barry JP, Chan F, English CA, Galindo HM, Grebmeier JM, Hollowed AB, Knowlton N, Polovina J, Rabalais NN, Sydeman WJ, Talley LD (2012) Climate change impacts on marine ecosystems. Annu Rev Mar Sci 4:11-37

FAO 2009 Introduction Cochrane K, De Young C, Soto D, Bahri $\mathrm{T}$ (eds) In: Climate change implications or fisheries and aquaculture. Overview of current scientific knowledge. Technical paper 530. FAO, Rome

FAO 2012 The State of World Fisheries and Aquaculture 2012. Rome. 209 pp 
Frusher SD, Hobday AJ, Jennings AM, Creighton C, D'Silva D, Haward M, Holbrook NJ, Nursey-Bray M, Pecl GT, Ingrid van Putten E (2013) The short history of research in a marine climate change hotspot: from anecdote to adaptation in south-east Australia. Rev Fish Biol Fish. doi:10. 1007/s11160-013-9325-7

Halpern BS, Walbridge S, Selkoe KA, Kappel CV, Micheli F, D'Agrosa C, Bruno JF, Casey KS, Ebert C, Fox HE, Fujita R, Heinemann D, Lenihan HS, Madin EMP, Perry MT, Selig ER, Spaulding M, Steneck RS, Watson R (2008) A global map of human impact on marine ecosystems. Science 319:948-952

Hamon KG, Frusher SD, Little LR, Thébaud O, Punt AE (2013). Adaptive behaviour of fishers to external perturbations: simulation of the Tasmanian rock lobster fishery. Rev Fish Biol Fish. doi:10.1007/s11160-013-9302-1

Hobday AJ, Evans K (2013) Detecting climate impacts with oceanic fish and fisheries data. Clim Change 119:49-62. doi: 10.1007/s10584-013-0716-5

Hobday AJ, Pecl GT (2013). Identification of global marine hotspots: sentinels for change and vanguards for adaptation action. Rev Fish Biol Fish. doi:10.1007/s11160-013-9326-6

Hobday AJ, Poloczanska ES, Matear R (2008) Implications of climate change for Australian fisheries and aquaculture: a preliminary assessment. Report to the Department of Climate Change, Canberra, Australia. August 2008. Available from http://www.cmar.csiro.au/climateimpacts/reports.htm

Jung S, Pang I-C, Lee J-H, Choi I, Cha HK (2013). Latitudinal shifts in the distribution of exploited fishes in Korean waters during the last 30 years: a consequence of climate change. Rev Fish Biol Fish. doi:10.1007/s11160-0139310-1

Mangubhai S, Strauch AM, Obura DO, Stone G, Rotjan RD (2013). Short-term changes of fish assemblages observed in the near-pristine reefs of the Phoenix Islands. Rev Fish Biol Fish. doi:10.1007/s11160-013-9327-5

Matear RJ, Chamberlain MA, Sun C, Feng M (2013) Climate change projection of the Tasman Sea from an eddy-resolving ocean model. J Geophys Res Oceans 118:2961-2976

Melnychuk MC, Banobi JA, Hilborn R (2013) The adaptive capacity of fishery management systems for confronting climate change impacts on marine populations. Rev Fish Biol Fish. doi:10.1007/s11160-013-9307-9

Maxwell SM, Hazen EL, Bograd SJ, Halpern BS, Breed GA, Nickel B, Teutschel NM, Crowder LB, Benson S, Dutton PH, Bailey H, Kappes MA, Kuhn CE, Weise MJ, Mate B, Shaffer SA, Hassrick JL, Henry RW, Irvine L, McDonald BI, Robinson PW, Block BA, Costa DP (2013) Cumulative human impacts on marine predators. Nat Commun 4:2688. doi: $10.1038 /$ ncomms 3688

Morley SA, Belchier M, Sands C, Barnes DKA, Peck LS (2013) Geographic isolation and physiological mechanisms underpinning species distributions at the range limit hotspot of South Georgia. Rev Fish Biol Fish. doi:10.1007/ s11160-013-9308-8

Okey TA, Alidina HM, Lo V, Jessen S (2013) Effects of climate change on Canada's Pacific marine ecosystems: a summary of scientific knowledge. Rev Fish Biol Fish. doi:10.1007/ s11160-014-9342-1

Poloczanska ES, Brown CJ, Sydeman WJ, Kiessling W, Schoeman DS, Moore PJ, Brander K, Bruno JF, Buckley LB, Burrows MT, Duarte CM, Halpern BS, Holding J, Kappel CV, O'Connor MI, Pandolfi JM, Parmesan C, Schwing F, Thompson SA, Richardson AJ (2013) Global imprint of climate change on marine life. Nat Clim Change. doi:10. 1038/NCLIMATE1958

Pecl G, Frusher S, Sauer W, Hobday A (2010) 2010 Sendai workshop on "Networking across Global Marine Hotspots". In: Climate change effects on fish and fisheries Sendai, Japan, vol 18. PICES Press, pp 26-28

Pecl G, Bates AE, Frusher S, Hobday A, Sauer W, Tobin RC, Vousden D, Wernberg T (2012) 2012 Yeosu workshop on "Climate change and range shifts in the oceans: detection, prediction and adaptation", vol 20. PICES Press, pp 24-27

Potts WM, Booth AJ, Richardson TJ, Sauer WHH (2013) Ocean warming affects the distribution and abundance of resident fishes by changing their reproductive scope. Rev Fish Biol Fish. doi:10.1007/s11160-013-9329-3

Rice JC, Garcia SM (2011) Fisheries, food security, climate change, and biodiversity: characteristics of the sector and perspectives on emerging issues. ICES J Mar Sci. doi:10. 1093/icesjms/fsr041

Teh LCL, Sumaila UR (2013) Contribution of marine fisheries to worldwide employment. Fish Fish 14:77-88. doi:10. 1111/j.1467-2979.2011.00450.x

Wu L, Cai W, Zhang L, Nakamura H, Timmermann A, Joyce T, McPhaden MJ, Alexander M, Qiu B, Visbeck M, Chang P, Giese B (2012) Enhanced warming over the global subtropical western boundary currents. Nat Clim Change. doi:10.1038/NCLIMATE1353

Yemane D, Kirkman SP, Kathena J, N'siangango SE, Axelsen B, Samaai T (2014) Assessing changes in the distribution and range size of demersal fish populations in the Benguela Current Large Marine Ecosystem. Rev Fish Biol Fish. doi:10.1007/s11160-014-9357-7 